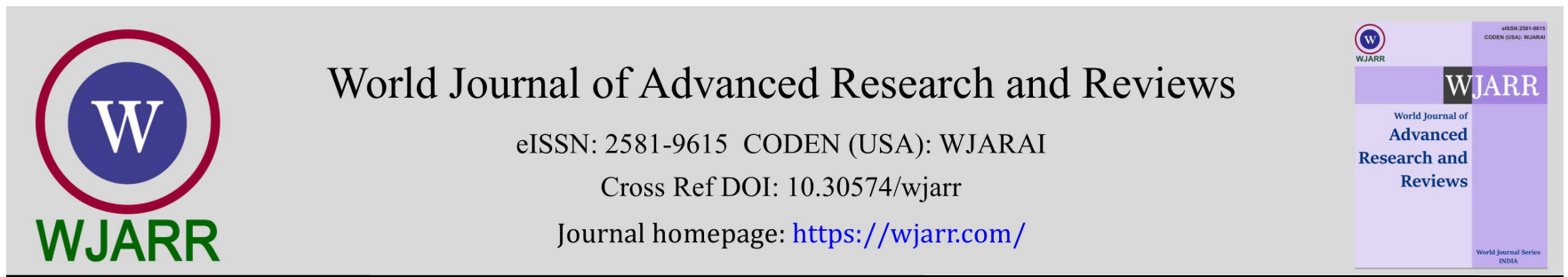

(RESEARCH ARTICLE)

\title{
Adverse drug reactions amongst admitted advanced age Africans
}

\author{
Ekechi Stella AMADI $1{ }^{*}{ }^{*}$, Erinma Fortuna PEPPLE ${ }^{2}$, Bolaji OTIKE-ODIBI ${ }^{3}$ and Hope Ilanye BELL-GAM ${ }^{4}$ \\ ${ }^{1}$ Dermatology Unit, Department of Internal Medicine, Rivers State University, Nkpolu-Oroworukwo, Rivers State, Nigeria \\ ${ }^{2}$ Community Medicine Department, Rivers State University, Nkpolu-Oroworukwo, Rivers State, Nigeria. \\ ${ }^{3}$ Dermatology Unit, Department of Internal Medicine, University of Port Harcourt Teaching Hospital, Rivers State, \\ Nigeria. \\ ${ }^{4}$ Geriatrics Unit, Department of Internal Medicine, Rivers State University, Nkpolu-Oroworukwo, Rivers State, Nigeria.
}

World Journal of Advanced Research and Reviews, 2021, 12(03), 427-433

Publication history: Received on 14 November 2021; revised on 23 December 2021; accepted on 25 December 2021

Article DOI: https://doi.org/10.30574/wjarr.2021.12.3.0712

\begin{abstract}
Background: Medical therapy amongst advanced age adults sometimes have its inherent significant risks such as adverse drug reactions (ADRs) resulting from the drug itself or drug-drug interactions or interactions from other substances such as alcohol.
\end{abstract}

Aim: The main aim of this study is to highlight ADRs noticed by the older adult while on admission either in the past or present with the goal of preventing them and improving treatment outcomes.

Methods: A purposive cross-sectional sampling of 126 elderly patients that were admitted to the different wards of the hospital within a 3-month period was carried out of which 25 older adults who met the criteria of being able to recall ADRs in the past or during current admission were included in the study.

Results: ADR was reported in a ratio of M: F ratio of 1:1.08 with a prevalence of $19.8 \%$ of the total older patients evaluated.

Conclusion: Self-reported ADRs amongst these advanced age in-patients were high. The actual number of adverse drug events may be higher if they actually looked out for by the physicians or other health care workers. The use of screening tools by physicians and other prescribing health workers can help in curbing adverse drug events in older adults.

Keywords: Adverse; African; Drug; Elderly; Reaction

\section{Introduction}

The World Health Organization (WHO) defines an adverse drug reaction (ADR) as noxious and unintended response to a drug, which occurs at normal doses used in human beings for the prophylaxis, diagnosis, or therapy of disease, or for the modifications of physiological function [1]. The older age group have been observed to be more susceptible to adverse drug reactions.[2, 3] The risk factors include frailty resulting from the aging process that affects the pharmacodynamics and pharmacokinetics of the advanced age adult leading to low physiological reserves, this predisposes to multi-morbidity and in turn predisposes to poly-pharmacy [3].The older age group are also disadvantaged from lack of participating in clinical trials and post marketing surveillance carried out because of several contraindications and age restricted limitations such as impaired memory in recalling side effects of drugs. The predisposition to s several co-morbidities may also impair caregivers and healthcare workers from easily identifying

\footnotetext{
* Corresponding author: Amadi ES

Dermatology Unit, Department of Internal Medicine, Rivers State University, Nkpolu-Oroworukwo, Rivers State, Nigeria.

Copyright $(2021$ Author(s) retain the copyright of this article. This article is published under the terms of the Creative Commons Attribution Liscense 4.0.
} 
ADRs [3, 4] Few studies exist in Africa that has focused on ADRs in the various populations particularly in the advanced age group [5,6]. This study aims to provide insight to the prevalence of ADRs, common drugs implicated and the adverse events self -reported by the advanced age group admitted into the wards of a tertiary health institution in a Sub Saharan African (SSA) country.

\section{Material and methods}

\subsection{Study area}

The study took place in the University of Port Harcourt Teaching Hospital (UPTH). The hospital is a 700-bed tertiary hospital located in Port Harcourt, Rivers state, Nigeria. The hospital plays host to a variety of medical specialists and serves as a referral center for other health care facilities in the state and neighbouring states as well.

\subsection{The study population}

The study population included persons aged 60 years and above presenting to University of Port Teaching Hospital, Alakahia for medical attention who were admitted to the wards after presentation.

\subsection{Sample and Sampling}

A purposive cross-sectional sampling of 126 elderly patients that were admitted to the different wards of the hospital within a 3-month period was carried out of which 25 older adults who met the criteria of being able to recall ADRs in the past or during current admission were included in the study.

\subsection{Data Collection}

A pro forma data collection sheet was used to collate bio data which included age, sex, marital status, level of education and occupation; ADR experienced in the past or during current admission and the route of administration, the dose of the drug, duration of the medication and the intervention carried out to reduce the effect of the ADR. Their diagnoses were also noted via the hospital folders and current medication had to be confirmed from the hospital folders.

\subsection{Data Analysis}

The data collected was analysed using the Statistical Package for Social Sciences (SPSS) v25 software. At a 95\% confidence interval and a p-value less than 0.05 was considered significant. The socio- demographic characteristics, clinical details and dermatological complains were presented in tables for better visualization.

\section{Limitation}

This study is based on collation of a self-reported data that is subject to recall bias by the respondents.

\section{Results}

Table 1 Summary of all Adverse Drug Reactions reported

\begin{tabular}{|c|c|c|c|}
\hline ADR & Frequency & $\%$ & Drugs implicated \\
\hline Abdominal pain & 2 & 4.0 & IV Cisplastin, IV ciprofloxacin \\
\hline Alopecia & 1 & 2.0 & IV Cisplastin \\
\hline Angioedema & 3 & 6.0 & $\begin{array}{l}\text { Sulfadoxine/Pyrimethamine } \\
\text { maleate(Piriton)® Allopurinol }\end{array} \quad$ (Fansidar)®, $\quad$ chlorphenamine \\
\hline Anorexia & 2 & 4.0 & Chloroquine, Artemisinin derivative \\
\hline Dizziness & 4 & 8.0 & Allopurinol, Amlodipine, Ceftriaxone, Methyldopa \\
\hline Drowsiness & 5 & 10.0 & Ceftriaxone, Chloroquine, Fansidar®, Methyldopa, Unknown BP drug, \\
\hline Dyspepsia & 1 & 2.0 & Vitamin C \\
\hline Erythroderma & 1 & 2.0 & Allopurinol \\
\hline
\end{tabular}




\begin{tabular}{|l|l|l|l|}
\hline Extreme weakness & 2 & 4.0 & $\begin{array}{l}\text { HAART(Tenofovir/Lamivudine/Efavirenz) } \\
\text { Acetaminophen (IM Paracetamol@) }\end{array}$ \\
\hline Fixed drug reaction & 1 & 2.0 & Sulphur containing drugs \\
\hline Hyperpigmentation & 3 & 6.0 & Amlodipine, IV Cisplastin, \\
\hline Itching & 11 & 22.0 & Chloroquine, Fansidar $囚$, Sulphur containing drugs, Quinine \\
\hline Insomnia & 2 & 4.0 & Chloroquine, Artemisinin derivative \\
\hline Palpitations & 1 & 2.0 & Salbutamol inhaler \\
\hline Rash & 3 & 6.0 & Unknown medication, Folic acid \\
\hline Restlessness & 4 & 8.0 & Amoxicillin, Ceftriaxone, Ciprofloxacin Methyldopa, \\
\hline Tachycardia & 2 & 4.0 & Salbutamol inhaler, Salbutamol nebuliser \\
\hline Tachypnoea & 1 & 2.0 & Salbutamol inhaler \\
\hline Vomiting & 1 & 2.0 & IV Ciprofloxacin \\
\hline Total & 50 & 100 & - \\
\hline
\end{tabular}

All drugs are per oral (PO) except otherwise stated. IM- Intramuscular, IV- intravenous, HAART- Highly Active Antiretroviral Therapy

Table 2 Drugs most commonly implicated and side effects

\begin{tabular}{|c|c|c|c|}
\hline Drugs & Side effects reported & $\begin{array}{l}\text { Total number of } \\
\text { adverse side effects }\end{array}$ & $\begin{array}{l}\text { Frequency } \\
\quad(\%)\end{array}$ \\
\hline Allopurinol & Dizziness, Erythroderma, & 2 & 4 \\
\hline Amlodipine & Dizziness, Hyperpigmentation, Rash & 4 & 8 \\
\hline $\begin{array}{l}\text { Artemisinin } \\
\text { derivative }\end{array}$ & Itching, Anorexia, Insomnia & 3 & 6 \\
\hline Chloroquine & Itching, Drowsiness, Anorexia & 12 & 24 \\
\hline Ciprofloxacin & $\begin{array}{l}\text { Abdominal pain, Vomiting, } \\
\text { Restlessness }\end{array}$ & 3 & 6 \\
\hline \multirow[t]{2}{*}{ Salbutamol } & $\begin{array}{l}\text { Palpitations, } \\
\text { Tachypnoea }\end{array}$ & 4 & 8 \\
\hline & & 28 & 56 \\
\hline Others & & 22 & 44 \\
\hline Total & & 50 & 100 \\
\hline
\end{tabular}

Table 3 ADR and systemic involvement

\begin{tabular}{|l|l|c|c|}
\hline S/N & \multicolumn{1}{|c|}{ Systems } & Frequency of ADR & $\mathbf{\%}$ \\
\hline 1 & Cardiovascular & 3 & 6 \\
\hline 2 & Central Nervous & 17 & 34 \\
\hline 3 & Gastrointestinal & 6 & 12 \\
\hline 4 & Integumentary/Skin & 23 & 46 \\
\hline 5 & Respiratory & 1 & 2 \\
\hline
\end{tabular}


Table 4 Medical ailment in the elderly

\begin{tabular}{|c|l|c|c|}
\hline S/N & \multicolumn{1}{|c|}{ Medical ailment } & Frequency & \% of Respondents \\
\hline 1 & Cancers & 4 & 16 \\
\hline 1 & Cataracts & 2 & 8 \\
\hline 2 & Chronic liver disease(CLD) & 2 & 8 \\
\hline 3 & Chronic Obstructive Pulmonary Disease(COPD) & 1 & 4 \\
\hline 4 & Dementia & 1 & 1 \\
\hline 5 & Diabetes Mellitus & 11 & 44 \\
\hline 6 & Dyspepsia/Peptic Ulcer Disease(PUD) & 7 & 28 \\
\hline 7 & HIV & 1 & 4 \\
\hline 8 & Hypertension & 21 & 84 \\
\hline 9 & Stroke & 5 & 20 \\
\hline
\end{tabular}

This study focuses on the self -reported adverse effect of drugs of elderly patients admitted into the wards of University of Port Harcourt Teaching Hospital, Alakahia who were being evaluated for skin disorders. Adverse drug effects or adverse drug reactions (ADR) was reported in a ratio of M: F ratio of 1:1.08 with a prevalence of $19.8 \%$ of the total older patients evaluated. Majority of the patients were Nigerians while one was a Ghanaian male. Majority of the persons had a tertiary education (52\%), married (68\%) and were retired from active duties (52\%). About $12.7 \%$ (16) of the older adults have experienced an adverse drug effect in the past. Females 8.7\% (11) could recall adverse effects of drugs in the past more than the males $4.0 \%$ (5). The average age for those with ADR to past medication was $68.13 \pm 3.66$ at $95 \%$ confidence interval (CI) and the age range being 60-88 years. Chloroquine an antimalarial was the most frequent drug implicated. Those who had ADR on current medication were 11.1\% (14). Males 7.1\% (9) complained of ADRs in this case more than females $4.0 \%$ (5). Amongst this number $35.7 \%$ (5) have experienced an adverse drug effect to more than one drug. Those with adverse effects to multiple drugs $20 \%$ (1) patient reported adverse effects to three different drugs. The remaining $80 \%$ (4) could recall past adverse effects to two drugs. The average age of those who experienced an ADR during their current admission was $72.07 \pm 5.32$ at $95 \%$ confidence interval and the age range was $61-93$. The average age for all the older adults with ADRs was $70.36 \pm 3.516$ at $95 \%$ CI. Out of those who reported ADR amongst the older adults evaluated, $4.0 \%$ (5) reported an ADR to both a past medication and a current medication in M: F ratio of 2:3. The total number of ADR reported for all the aged adults were 50. Unknown medication was the frequent response causing ADR amongst the seniors during their current admission. This response was given by 3 respondents with males being predominant. They were on multiple medications and they were not sure which medication was actually causing the side effect. Brownish discolouration of teeth was noted by a female patient who was on tetracycline, metronidazole, pentacozine, and diclofenac. Hyperpigmentation of the face and hands was seen in two male patients who were on amlodipine, hydrochlorothiazide, salbutamol inhaler PRN and amlodipine, insulin, cholestryamine, and metformin respectively. The later patient also experienced itching, rash and had excoriation marks. He was a known hypertensive with hepatitis being evaluated for chronic liver disease. Allopurinol was the next drug that was frequently implicated in causing adverse effects. Allopurinol was associated with prolonged use of the drug before the occurrence of the adverse drug reaction.

Hypertension which was the major medical ailment was complicated by congestive cardiac failure in 23.8\% (5) older adults. The cancers reported were right breast cancer (male), Non- Hodgkin's lymphoma, advanced metastatic prostate cancer and advanced endometrial cancer. A great majority of them, 96\% (24) had multiple morbidities. A higher percentage $96 \%$ (24 of 25) of those with ADRs were on more than 5 drugs when compared to 86.14\% (87of 101 ) of those without ADRs. There was no statistical difference with regards to poly pharmacy between those with selfreported ADR and those without ADR complaints. The major categories of drugs that the elderly were on are antihypertensives, antimalarial, antibiotics, analgesics, antacids and anti-diabetic medications.

Those older adults with self- reported ADR were 3.5 times more likely to have significant alcohol intake than those without any reported ADR. The ADRs could be described as Type A reactions (dose related reactions) in $80 \%$ of cases. While Type B reactions consisted of $20 \%$ of ADR. The likely type B reactions included angioedema caused by sulfadoxine/pyrimethamine combination, Piriton $®$ (chlorphenamine) and allopurinol; erythroderma caused by allopurinol, extreme weakness caused a dose of IM Paracetamol, hyperpigmentation caused by amlodipine, fixed drug reaction by sulphur containing drugs, insomnia caused by chloroquine and artemisinin derivatives and rash caused by 
folic acid. Majority (96\%) of the ADR reported were from appropriate prescribing of drugs while a patient who suffered from hypertension complicated by CCF was inappropriately prescribed salbutamol inhaler by a patent medicine drug dealer for his breathlessness in assumption he had asthma. In $90 \%$ of the witnessed ADR the medication had to be stopped.

\section{Discussion}

The prevalence of self -reported ADR among the population of advanced age adults was higher when compared to other studies of similar groups in similar settings which were $10.7 \% 10 \%, 8.7 \%$ and $0.23 \%$ respectively [6-9]. Other studies which were carried out in hospitalized settings that focused on observing ADR among various admitted older adult groups had higher prevalence of $23.1 \%, 46.3 \%$ and $61.8 \%$ respectively [10-12]. This variation in prevalence may be due to the larger number of persons being studied, the selection criteria and settings in which the study was carried out. The median age of the elderly was similar to other studies done [7-9,10,12]. Females were more in making complaints of ADRs as seen in another study [11]. Another study done within the same geographical region showed more males although the age range consisted mainly of a younger age group [13]. Although in this study more women could recall ADR to past medication while the reverse was the case for those who were currently on admission. The ability to report discomfort to drugs have been noted to be higher in females when compared to males and they are more likely to remember and avoid these medication as noted in a review[14]. Antimalarial agents (chloroquine, quinine, sulfadoxine/pyrimethamine), antibiotics (amoxicillin, ciprofloxacin and ceftriaxone) and anti-hypertensives (amlodipine and methyldopa) were the most common classes of drugs implicated in ADR in the elderly as seen in Table 1. This finding is similar to a study done in admitted adults in an African population $[5,13]$. This is understandable as infectious diseases are still more prevalent in Africa and being dark skinned African is a risk factor for hypertension. Anti-hypertensives and other cardiovascular medicine have also been reported to be a major cause of ADRs in older adults although of non-African origin [3-4, 11-12]. Medications of unknown identity (MUIs) have been implicated in ADR as well as seen in other studies $[15,16]$. Factors that can affect this include the educational status of the older adult, drug-drug interactions and poor labelling of drugs [9-10,14-17]. ADRs are known to commonly manifest on the skin as this study reflects this which is similar to other studies $[8,10]$.These are mainly due to hypersensitivity reactions such as skin rash and pruritus which is a reflection of the immunologic functions of the skin[10, 16, 18. Cutaneous adverse drug reaction are commonly due to unknown medication just as this study showed two patients with hyperpigmentation due to an unknown medication, however the suspected drug is likely to be amlodipine since it was the drug both patients had in common [16]. Hyperpigmentation due to amlodipine has been reported in case reports as seen in this study $[19,20]$. The exact mechanism of pigment formation is unknown but generally mechanisms of drug induced skin pigmentation has been proposed to occur by stimulation of melanin synthesis and its accumulation worsened by sun exposure or degradation of the drug and its uptake by dermal macrophages. Drugs that have been frequently implicated in causing skin pigmentation are non-steroidal anti-inflammatory drugs, anti-malarial drugs, amiodarone, cytotoxic drugs, tetracyclines especially minocycline, heavy metals and psychotropic drugs [21]. Allopurinol has been implicated as a cause of varying cutaneous ADR in several studies in different populations and its effect can be fatal particularly in the elderly. The major reason for prescribing is due to hyperuricemia as it was so in the index case with erythroderma $[22,23]$. Brownish discolouration of the teeth is known to be caused by tetracycline in children; however in the elderly this has not been reported. Old age can also be a risk factor for brownish discolouration of the teeth in itself [24]. Gastrointestinal side effects are the commonest side effects of floroquinolones such as ciprofloxacin in the elderly as this study portrays [25]. Chloroquine induced pruritus is a common finding amongst Africans $[26,27]$. It may not be responsive to anti-histamine like chlorpheniramine and it is a common cause of cessation of the medication[ 26, 28].The mechanism proposed is that chloroquine or its metabolite (monodesethylchloroquine) act as haptens; binding to break down products of parasitized erythrocytes or possibly interacting with acetyl-glyceryl-ether-phosphoryl-choline (AGEPC), This resulting complex act as an antigen, triggering reaginic antibodies (IgE) that bind to the surface of mast cells and basophils which stimulate several mediators such as histamine, prostaglandin, substance $\mathrm{P}$ and bradykinin directly impinging on sensory nerves leading to itching. Other antimalarial drugs have also been implicated in causing pruritus as seen in this study [26]. Salbutamol is also one of the commonest drugs implicated as causing ADR in this study. The side effects are all expected however, the only inappropriate drug use seen in this study was associated with salbutamol. Inappropriate drug use commonly arises from self-medication, using over the counter medication which is a common problem in the elderly [29, 30]. Central nervous systemic symptoms are also common manifestations of ADRs in the elderly [3, 10, 14]. Polypharmacy and multimorbidity which are potential risk factors for ADR in advanced aged patients were characteristics seen within this study just as several studies has shown; $[3,4,10,14,18]$ however it was not comparatively different from the older age group without reported ADR. Alcohol intake even in moderate quantities have been associated with adverse drug reactions in the elderly as this study also reflects[31, 32 ].The ADRs were mainly Type A(dose dependent) reactions, this finding is similar to several studies done in the elderly[3, 4, 8, 18].Discontinuing the medication was done in majority of the cases as seen in this study helped in resolution of symptoms as it is recommended and has been shown 
to reduce the harm in majority of cases as seen in other studies[8, 33, 34]. Other strategies to reduce the risk of ADRs in the older patient include, prescribing new medications sparingly, curtailing the number of prescribers, and frequently reconciling medications. The Beers, STOPP (screening tool of older persons' potentially inappropriate prescriptions), and START (screening tool to alert doctors to right treatment) criteria are tools that have been proven to aid in curbing adverse drug events in older adults $[33,34]$.

\section{Conclusion}

Self-reported ADRs amongst these advanced age in-patients were high. The actual number of adverse drug events may be higher if they actually looked out for by the physicians or other health care workers. The use of screening tools by physicians and other prescribing health workers can help in curbing adverse drug events in older adults.

\section{Compliance with ethical standards}

\section{Disclosure of conflict of interest}

No conflict interest.

\section{Statement of ethical approval}

Ethical approval to carry out the study was obtained from the Research and Ethics Committee of the University of Port Harcourt Teaching Hospital before commencing the study.

\section{Statement of informed consent}

A willing written informed consent was obtained from each participant before they were included into the study.

\section{References}

[1] WHO definitions. Adverse drug Reactions.

[2] Coleman JJ, Pontefract SK. Adverse drug reactions. Clin Med(Lond). 2016; 16(5): 481-485.

[3] Davies EA, O'Mahony MS. Adverse drug reactions in special populations - the elderly. Br J Clin Pharmacol. 2015 Oct; 80(4): 796-807.

[4] Brahma DK, Wahlang JB, Marak MD, Ch Sangma M. Adverse drug reactions in the elderly. J Pharmacol Pharmacother. 2013; 4(2): 91-94.

[5] Cliff-Eribo, KO. Adverse drug reactions in West Africa.

[6] Aderemi-Williams RI, Awodele 0, Boyle CA. Adverse drug reactions amongst adult patients admitted in Lagos State University Teaching Hospital Lagos, Nigeria. Curr Drug Saf. 2015; 10(2): 136-44.

[7] Chrischilles EA, Segar ET, Wallace RB. Self-reported adverse drug reactions and related resource use. A study of community-dwelling persons 65 years of age and older. Ann Intern Med. 1992 Oct 15; 117(8): 634-40.

[8] Jose J, Rao PG. Pattern of adverse drug reactions notified by spontaneous reporting in an Indian tertiary care teaching hospital. Pharmacol Res. 2006 Sep; 54(3): 226-33.

[9] Thomson, J.A., Wang, W.C., Browning, C. et al. Self-reported medication side effects in an older cohort living independently in the community - the Melbourne Longitudinal Study on Healthy Ageing (MELSHA): crosssectional analysis of prevalence and risk factors. BMC Geriatr. 2010; 10: 37.

[10] Outi Laatikainen, Sami Sneck, Risto Bloigu, Minna Lahtinen, Timo Lauri, Miia Turpeinen. Hospitalizations Due to Adverse Drug Events in the Elderly-A Retrospective Register Study, Front. Pharmacol. 2016, Oct 5

[11] Alhawassi TM, Krass I, Bajorek BV, Pont LG. A systematic review of the prevalence and risk factors for adverse drug reactions in the elderly in the acute care setting. Clin Interv Aging. 2014; 9: 2079-86.

[12] Passarelli MC, Jacob-Filho W, Figueras A. Adverse drug reactions in an elderly hospitalised population: inappropriate prescription is a leading cause. Drugs Aging. 2005; 22(9): 767-77. 
[13] Akhideno, PE, Fasipe OJ, Isah, AO, Owhin, OS, Adejumo, OA. Pattern of medications causing adverse drug reactions and the predisposing risk factors among medical in-patients in clinical practice: A prospective study, Journal of Medical Sciences. 2019; 39(10): 18-27.

[14] Alomar MJ. Factors affecting the development of adverse drug reactions, Saudi Pharm J. 2014; 22(2): 83-94.

[15] Caillet C, Sichanh C, Assemat G, et al. Role of Medicines of Unknown Identity in Adverse Drug Reaction-Related Hospitalizations in Developing Countries: Evidence from a Cross-Sectional Study in a Teaching Hospital in the Lao People's Democratic Republic. Drug Saf. 2017; 40(9): 809-821.

[16] Shah, SP, Desai, MK, Dikshit, RK. Analysis of Cutaneous Adverse Drug Reactions at a Tertiary Care Hospital - a Prospective Study, Tropical Journal of Pharmaceutical Research. 2011; 10(4).

[17] Mirosevic Skvrce N, Macolic Sarinic V, Mucalo I, Krnic D, Bozina N, Tomic S. Adverse drug reactions caused by drug-drug interactions reported to Croatian Agency for Medicinal Products and Medical Devices: a retrospective observational study. Croat Med J. 2011; 52(5): 604-614.

[18] Alsbou M, Alzubiedi S, Alzobi H, Samhadanah NA, Alsaraireh Y, Alrawashdeh O, Aqel A, Al-Salem K. Adverse drug reactions experience in a teaching hospital in Jordan. Int J Clin Pharm. 2015 Dec; 37(6): 1188-93.

[19] Erbagci Z. Amlodipine associated hyperpigmentation. Saudi Med J. 2004 Jan; 25(1): 103-105.

[20] Murthy, MB, Murthy, B Amlodipine-induced petechial rash. ADR Report. 2011; 57(4): 341-342.

[21] Dereure 0. Drug-Induced Skin Pigmentation: Epidemiology, Diagnosis and Treatment, 2001, American Journal of Clinical Dermatology. 2(4): 253-62.

[22] Khoo BP, Leow YH. A review of inpatients with adverse drug reactions to allopurinol. Singapore Med J. 2000 Apr; 41(4): 156-60.

[23] Scavone C, Di Mauro C, Ruggiero R, et al. Severe Cutaneous Adverse Drug Reactions Associated with Allopurinol: An Analysis of Spontaneous Reporting System in Southern Italy. Drugs Real World Outcomes. 2020; 7(1): 41-51.

[24] Cleeveland Clinic. Tooth Discolouration.

[25] Stahlmann R, Lode H. Fluoroquinolones in the elderly: safety considerations. Drugs Aging. 2003; 20 (4): $289-302$.

[26] Aghahowa SE, Obianwu HO, Isah AO, Arhewoh IM. Chloroquine-induced Pruritus. Indian J Pharm Sci. 2010; 72(3): 283-289.

[27] Osifo NG. Chloroquine-Induced Pruritus among Patients with Malaria. Arch Dermatol. 1984; 120(1): 80-82.

[28] Mnyika KS. The efficacy of Piriton $®$ on chloroquine-induced pruritus in patients with malaria. East Afr Med J. Feb 1991; 68(2): 139-42..

[29] Locquet M, et al. Adverse Health Events Related to Self-Medication Practices Among Elderly: A Systematic Review. Drugs Aging. 2017 May; 34(5): 359-365.

[30] Zazzara MB, Palmer K, Vetrano DL, et al. Adverse drug reactions in older adults: a narrative review of the literature. Eur Geriatr Med. 2021; 12: 463-473.

[31] Onder G, et al. Moderate alcohol consumption and adverse drug reactions among older adults. Pharmacoepidemiology and Drug Safety. 2002; 11(5): 385-392.

[32] Pringle, KE, Ahern, FM, Heller, DA Gold, CH, Brown, TV. Potential for alcohol and prescription drug interactions in older people, J. Am. Geriatr. Soc. 2005; 53 (11): 1930-1936.

[33] Pretorius RW, Gataric G, Swedlund S, Miller JR. Reducing the Risk of Adverse Drug Events in Older Adults Am Fam Physician. 2013 Mar 1; 87(5): 331-336.

[34] Lavan AH, Gallagher P. Predicting risk of adverse drug reactions in older adults. Ther Adv Drug Saf. 2016; 7(1): 11-22. 